\title{
Nonlinear Creep Behavior and Viscoelastic-Plastic Constitutive Model of Rock-Concrete Composite Mass
}

\author{
Yang Liu, ${ }^{1}$ Da Huang, ${ }^{1}$ Baoyun Zhao $\mathbb{D}^{2,3,4}$ Chen Wang, ${ }^{5}$ and Duofeng Cen ${ }^{1}$ \\ ${ }^{1}$ School of Civil and Transportation Engineering, Hebei University of Technology, Tianjin 300401, China \\ ${ }^{2}$ School of Civil Engineering and Architecture, Chongqing University of Science and Technology, Chongqing 401331, China \\ ${ }^{3}$ Chongqing Key Laboratory of Energy Engineering Mechanics \& Disaster Prevention and Mitigation, Chongqing 401331, China \\ ${ }^{4}$ The Key Laboratory of Well Stability and Fluid \& Rock Mechanics in Oil and Gas Reservoir of Shaanxi Province, \\ Xi'an Shiyou University, Xi'an 710065, China \\ ${ }^{5}$ School of Petroleum Engineering, Chongqing University of Science and Technology, Chongqing 401331, China
}

Correspondence should be addressed to Baoyun Zhao; baoyun666@163.com

Received 8 January 2020; Revised 13 May 2020; Accepted 31 July 2020; Published 27 August 2020

Academic Editor: Dimitris Rizos

Copyright (c) 2020 Yang Liu et al. This is an open access article distributed under the Creative Commons Attribution License, which permits unrestricted use, distribution, and reproduction in any medium, provided the original work is properly cited.

The joint force deformation of rock-concrete composite structures is different from that of simple rock specimens or concrete specimens, such as the tunnel surrounding rock-lining concrete, dam foundations, and concrete. In order to study the creep mechanical properties of rock-concrete composite structures under long-duration load, the TFD-2000 microcomputer servo triaxial creep testing machine is used to carry out step loading creep tests on rock-concrete composite specimens (hereinafter referred to as composite specimens) under different confining pressures (including the confining pressures $\sigma_{3}=0 \mathrm{MPa}$ ). The creep test results show that, under the same confining pressure, when axial deviatoric stress is applied step-by-step according to $10 \%, 20 \%, 30 \%, 40 \%, 50 \%$, and so forth of the UCS ( $\sigma_{3}=0 \mathrm{MPa}$ ) and TCS (triaxial compressive strength) of the composite specimens, the failure stress that the specimen can bear is closely related to the confining pressure. When the confining pressures are $0 \mathrm{MPa}, 7 \mathrm{MPa}, 15 \mathrm{MPa}$, and $22 \mathrm{MPa}$, respectively, the failure stresses that the composite specimens can bear are $60 \%$ (corresponds to $0 \mathrm{MPa}$ ), $50 \%, 30 \%$, and $20 \%$ of the TCS under the current confining pressures, respectively. Under the same confining pressure, the initial creep rate of the composite specimen on each step shows a U-shaped change trend. Meanwhile, the instantaneous creep rate and failure creep rate of the specimen increase as the confining pressure increases. When the failure creep rate is excluded, the initial creep rate of other stepped loads at the same confining pressure level decreases step-by-step. The improved Nishihara model can better describe the whole creep process of rock-concrete composite specimens, especially in the accelerating creep step. The testing data and research results in this paper can serve as references for further research on mechanical properties of rock-concrete composite structures.

\section{Introduction}

Rock and concrete are two kinds of common building materials, with each containing differences in structure, mechanical properties, and chemical composition. These two materials are often combined together to bear various complex forces and deformations, such as dam concrete and dam foundation rock, tunnel surrounding rock and shotcrete, and concrete foundation and rock foundation [1-3]. The mechanical properties of rock-concrete composite structures is an essential parameter involved in the design and stability analysis of many engineering structures [4-6].
Therefore, it is of great value and significance to carry out studies on the mechanical properties of rock-concrete composite structures, especially the mechanical properties of rock-concrete composite structures under long-duration load. The schematic diagram of the rock-concrete composite structure in actual engineering is shown in Figure 1.

At present, abundant research studies on rock creep and concrete creep have been carried out, and many scholars have conducted extremely in-depth research studies on creep mechanical properties of rock. In Zhao et al.'s work [7], based on the experimental results at different stress conditions, an EVPR model that can represent the 


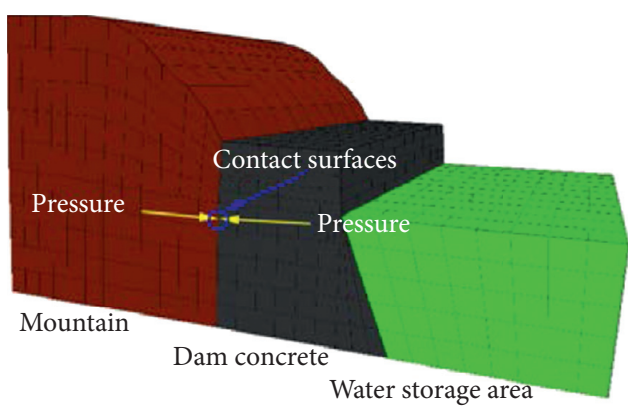

(a)

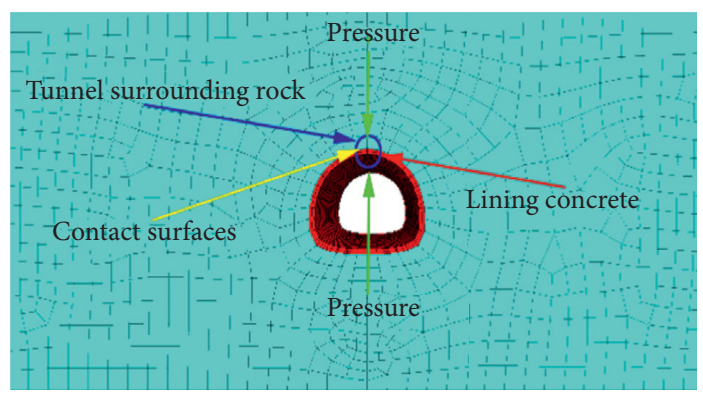

(b)

FIGURE 1: Schematic diagram of rock-concrete composite structure in actual engineering. (a) Dam bedrock-concrete structure. (b) Tunnel confining-lining concrete structure.

instantaneous elastic, instantaneous plastic, viscoelastic, and viscoplastic behaviors of hard rock was proposed. They believe that the EVPR model makes up for the shortcomings of some existing creep models of rock. Zhang et al. [8] performed a triaxial creep test of the surrounding rocks in the Fuxin Hengda coal mine using an MTS815.02 rock mechanics testing system and established a nonlinear creep damage model of the rocks. Hadiseh and Rassoul [9] investigated the mechanical characteristics of salt rock by using uniaxial compression creep tests in a salt diapir located in the south of Iran, and they found that the Nishihara model can well perform the creep process of salt rock under the condition without confining pressures. Nicholas et al. [10] analyzed the creep mechanism of two kinds of rocks by comparing quartz microstructures between deformed monomineralic and polymineralic rocks. Their research result provides a new method of rock creep test from microstructures. Meanwhile, there are some other scholars who have also carried out relevant researches on the concrete creep. He et al. [11] analyzed the compression creep mechanical behavior of concrete under the different test conditions. By conducting compression creep test on large cylinder specimens with different loading ages, they found that the creep mechanical behavior of concrete is closely related to the concrete curing time. Laurent et al. [12, 13] conducted a systematic study on the mechanical properties of concrete under long-duration load, focusing on the analysis and discussion of Young's modulus and Poisson's ratio, long-duration logarithmic strain, and viscoelastic creep Poisson's ratio. Their study result shows that, compared to instantaneous load, Young's modulus and Poisson's ratio of concrete under long-duration load are significantly different. Mounia et al. [14] studied the mechanical properties of concrete creep from different scales and especially discussed the creep model and residual strength of concrete. Their research result reveals that the creep process of concrete is similar to that of the rock and also can be divided into three stages.

In addition to above research on creep mechanical properties of rock and concrete, many scholars have shifted their focus to rock-concrete joint deformation. Alan and Jiang [15] simulated the rock-concrete composite lining structure by analyzing the relationship between the coordinated deformation of tunnel surrounding rock and concrete lining. Their study method is very effective to simplify the complexity of actual engineering and can well simulate mechanical properties of tunnel surrounding rock and concrete lining under long-duration load. Stavropoulou et al. [16] discussed the delayed mechanical behavior of rockconcrete composite specimen interface under shear stress. They believe that the interface of rock-concrete composite specimen is influenced by the physical properties of rock and concrete, respectively. Hussein et al. [17] and Maria et al. [18] through the actual engineering research of hydropower dam point out that the shear strength of concrete and rock interface is a key factor determined based on the stability of hydraulic structures. Zhao et al. [19] analyzed the basic mechanical properties of foamed concrete-rock composite and studied the bond-slip behavior of foamed concrete-rock contact surface. Their findings indicate that the surface adhesion of concrete-rock composite specimen mainly depends on the roughness of the concrete and rock. Wei et al. [20] discussed the fracture process of rock-concrete interface and carried out corresponding numerical simulation. They give a very reasonable explanation of the fracture process of rock-concrete interface from the micromechanical level.

Nevertheless, the above-mentioned researches mainly focus on the creep mechanical properties of single rock and single concrete or the triaxial compression, shear, and other mechanical properties of rock-concrete composite structures. There are few scholars $[21,22]$ who have studied and analyzed the long-duration mechanical properties of rockconcrete composite structures, that is, the creep properties of rock-concrete composite structures. Therefore, testing data and conclusions in the paper obtained through the relevant creep testing research on the long-duration mechanical properties of rock-concrete composite specimens can greatly enrich the research results of rock-concrete composite specimens and serve as references for the research of rockconcrete composite structures under long-duration load.

\section{Specimen Preparation and Test Equipment}

2.1. Specimen Preparation. In this paper, the composite specimen selected white sandstone as the research object, and the rock specimen is sampled from a highway tunnel in 
Chongqing of China. The rock has compact and uniform structure and white gray appearance. Its mineral components mainly include quartz, feldspar, calcite, and a small amount of iron, and its chemical components mainly include $\mathrm{SiO}_{2}, \mathrm{Al}_{2} \mathrm{O}_{3}, \mathrm{MgO}, \mathrm{CaO}$, and $\mathrm{Fe}_{2} \mathrm{O}_{3}$. By our previous related study [23], it was learned that the rock is brittle rock with low strength. In addition, the UCS (uniaxial compression strength) has been found to be equal to $30.56 \mathrm{MPa}$ and the average bulk density is $2431 \mathrm{~kg} / \mathrm{m}^{3}$. The elastic modulus and Poisson's ratio of the tested rock under uniaxial compression are $6.4 \mathrm{GPa}$ and 0.14 , respectively.

The concrete specimens are mixed in the laboratory according to the actual engineering conditions by using P42.5 ordinary Portland cement. All indexes shall meet the requirements of Standard Specification for Portland Cement [24]. The coarse aggregate is continuously graded crushed stones with a particle size ranging from $6 \mathrm{~mm}$ to $13 \mathrm{~mm}$, and all indexes meet the requirements of Standard Test Method for Sieve Analysis of Fine and Coarse Aggregates [25]. The fine aggregate is ordinary medium river sand, with the grading curve in Area II, and all its indexes meet the requirements of Standard Test Method for Relative Density (Specific Gravity) and Absorption of Fine Aggregate [26]. Tap water is used for mixing concrete, and the concrete is mixed in strict accordance with the Standard Practice for Sampling Freshly Mixed Concrete [27]. The mechanical properties of the concrete meet the requirements of [28]. The basic physical parameters of rock and concrete specimens are shown in Table 1.

As for the processing and manufacturing of rock-concrete composite specimens, the following steps were taken:

(1) Clean the upper surface of the rock and maintain a certain degree of roughness to facilitate the bonding of concrete and rock. The roughness of the upper surface of rock is caused by manual with graver.

(2) In order to ensure sufficient humidity on the upper surface of the rock before pouring the concrete, soak the rock in water for 24 hours in advance.

(3) Take the rock out from the water, put it into a steel mould, and pour concrete on the rough side of it after the surface of the rock is slightly dried to facilitate the forming of the rock-concrete composite test block.

(4) Manufacture $\Phi 50 \times(50+50) \mathrm{mm}$ cylindrical composite specimens in laboratory. The manufacturing of the specimens is strictly in accordance with the test procedures formulated by the International Society for Rock Mechanics (ISRM) (Fairhurst and Hudson [29]): standard cylinder specimens with a height of $100 \mathrm{~mm}$ and a diameter of $50 \mathrm{~mm}$ are manufactured, and the error of specimen diameter is no more than $0.3 \mathrm{~mm}$ and that of end face nonparallelism is no more than $0.05 \mathrm{~mm}$. The rock-concrete composite specimens are shown in Figure 2.

2.2. Test Equipment. Figure 3 shows the test equipment of TFD-2000 and deformation gauge. The test equipment consists of four parts, which are confining pressure control system, axial pressure control system, loading system, and computer service platform. The experiments were performed with the microcomputer servo-controlled triaxial rheological test machine. This equipment can be used to carry out conventional compression and rheological tests such as uniaxial and triaxial compression tests and triaxial rheological tests. The confining pressure ranged from 0 to $100 \mathrm{MPa}$ and the maximum axial test force of the equipment was $500 \mathrm{MPa}$. Furthermore, the axial displacement is measured by a pair of LVDTs having a measurement range of $0-10 \mathrm{~mm}$ with precision of $0.001 \mathrm{~mm}$. The radius change is measured by a circumferential ring that has a measurement range of $1.5 \mathrm{~mm}$ and precision of $0.001 \mathrm{~mm}$.

2.3. Test Process and Plan. In this paper, three composite specimens were tested under the same condition for all tests to reduce the experimental error. The specific testing steps concerning creep are as follows:

Step 1. The device installed with a rock-concrete composite specimens was fixed on the testing platform of triaxial compression test machine, and the pressure chamber was closed.

Step 2. The confining pressures are designed to be $0 \mathrm{MPa}, 7 \mathrm{MPa}, 15 \mathrm{MPa}$, and $22 \mathrm{MPa}$ in sequence according to the buried depth of the highway tunnel. The confining pressure $\sigma_{3}$ was loaded to the desired level, which makes the specimen be always in the stress state of $\sigma_{1}=\sigma_{2}=\sigma_{3}$ (namely, hydrostatic stress state) during the loading process of confining pressure. The confining pressure will remain constant in the subsequent axial loading process.

Step 3. According to the UCS and TCS of rock-concrete composite specimens under the same confining pressures, $10 \%, 20 \%, 30 \%$, and so forth of the peak axial deviatoric strengths are chosen in sequence until the specimens are in failure. The loading rate of each step is $0.5 \mathrm{MPa} / \mathrm{s}$ [30], and the loading of each step lasts about 24 hours.

In this paper, the reason why we select 24 hours for every step is that when the axial strain value is less than 0.001 , it can be deemed that the creep rate of the rock-concrete composite specimen will not change any more. The rockconcrete composite specimen enters into a stable state. So before the formal test, by observing several groups' rockconcrete composite specimens under creep tests, it was found that the 24-hour period is meeting the test requirements for each step. The test results of rock-concrete composite specimens with triaxial compression test (TCT) under different confining pressures are shown in Table 2. The specific creep test plans under different confining pressure are shown in Table 3.

\section{Test Results}

3.1. Stress Strain. The step loading time-stress-strain curves of rock-concrete composite specimens under different confining pressures are shown in Figures 4(a)-4(d). It can be 
TABLE 1: Basic physical parameters of rock and concrete specimens [23].

\begin{tabular}{|c|c|c|c|c|c|c|c|c|}
\hline Specimens name & & $\begin{array}{l}\text { Diameter, } d \\
(\mathrm{~mm})\end{array}$ & $\begin{array}{l}\text { Height, } h \\
\quad(\mathrm{~mm})\end{array}$ & $\begin{array}{l}\text { Density, } \rho \\
\left(\mathrm{kg} / \mathrm{m}^{3}\right)\end{array}$ & $\begin{array}{l}\text { Peak strength, } \\
\sigma-p c(\mathrm{MPa})\end{array}$ & $\begin{array}{c}\text { Elastic } \\
\text { Modulus, } E \\
(\mathrm{GPa})\end{array}$ & $\begin{array}{c}\text { Axial peak } \\
\text { strain, } \mathcal{E}^{-}{ }_{A}(\%)\end{array}$ & $\begin{array}{l}\text { Circumferential peak } \\
\text { strain, }{ }^{\mathcal{E}-}{ }(\%)\end{array}$ \\
\hline \multirow{4}{*}{ Rock specimens } & $\mathrm{R} 1$ & 49.87 & 99.62 & 2281 & 35.41 & 6.82 & 0.39 & 0.22 \\
\hline & $\mathrm{R} 2$ & 50.14 & 99.47 & 2294 & 65.19 & 5.94 & 0.66 & 0.34 \\
\hline & R3 & 49.75 & 99.58 & 2257 & 99.35 & 6.42 & 0.98 & 0.98 \\
\hline & $\mathrm{R} 4$ & 49.57 & 99.87 & 2275 & 116.01 & 5.81 & 0.91 & 0.88 \\
\hline \multirow{4}{*}{ Concrete specimens } & $\mathrm{C} 1$ & 49.04 & 99.56 & 2189 & 23.87 & 12.79 & 0.18 & 1.07 \\
\hline & $\mathrm{C} 2$ & 50.12 & 100.02 & 2145 & 70.19 & 13.45 & 0.42 & 0.59 \\
\hline & $\mathrm{C} 3$ & 49.75 & 100.15 & 2098 & 84.34 & 13.68 & 0.80 & 0.64 \\
\hline & $\mathrm{C} 4$ & 49.88 & 99.63 & 2136 & 97.33 & 13.82 & 1.70 & 2.00 \\
\hline
\end{tabular}
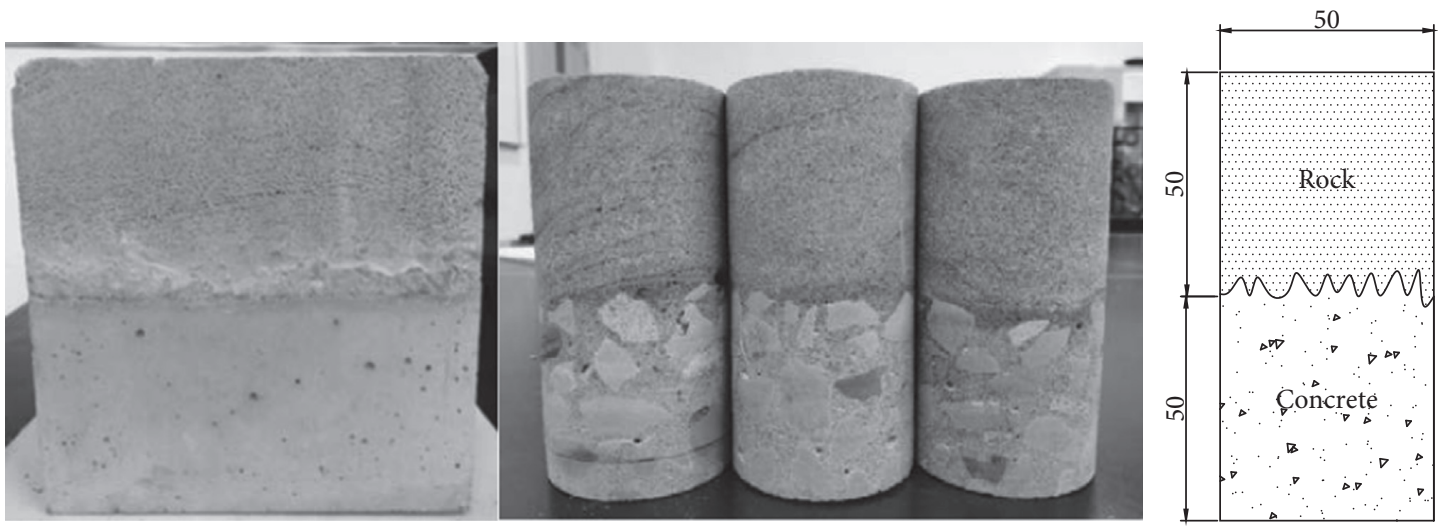

Figure 2: Pictures and schematic diagram of rock-concrete composite specimens.

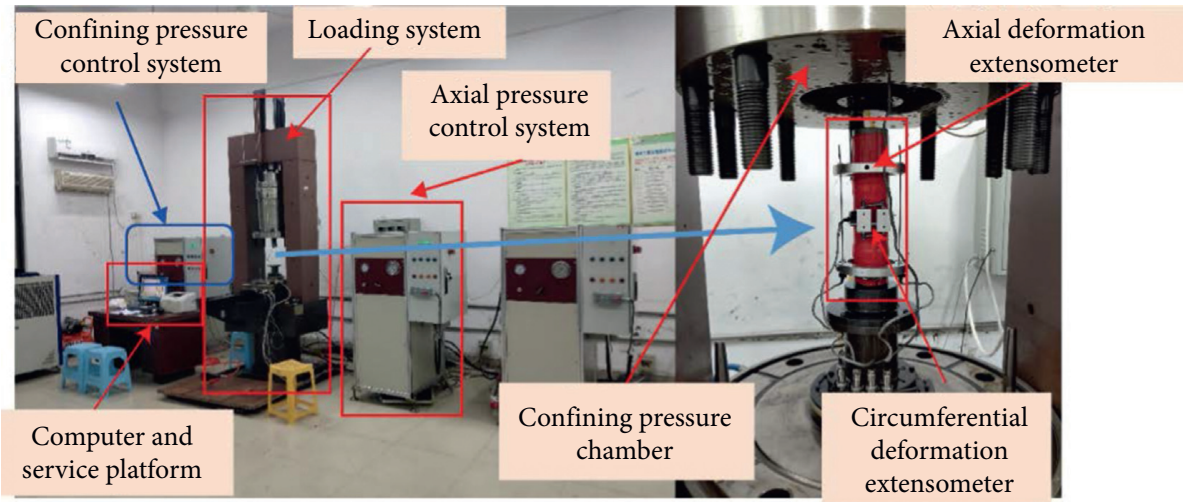

FigURE 3: Installation of the TFD-2000 microcomputer servo-controlled triaxial rheological testing machine for rock and deformation extensometer.

TABle 2: The test results of rock-concrete composite specimens with triaxial compression under different confining pressures [23].

\begin{tabular}{ccccccc}
\hline \multirow{2}{*}{$\begin{array}{c}\text { Rock-concrete } \\
\text { composite }\end{array}$} & $\begin{array}{c}\text { Confining } \\
\text { pressure, } \sigma_{3} \\
(\mathrm{MPa})\end{array}$ & $\begin{array}{c}\text { Peak axial deviatoric } \\
\text { stress, } \sigma_{\text {-pads }}(\mathrm{MPa})\end{array}$ & $\begin{array}{c}\text { Elastic } \\
\text { modulus, } E \\
(\mathrm{GPa})\end{array}$ & $\begin{array}{c}\text { Poisson's } \\
\text { ratio, } \mu\end{array}$ & $\begin{array}{c}\text { Axial peak } \\
\text { strain, } \varepsilon_{1}(\%)\end{array}$ & $\begin{array}{c}\text { Circumferential peak } \\
\text { strain, } \varepsilon_{3}(\%)\end{array}$ \\
\cline { 2 - 7 } (triaxial compression) & 0 & 30.56 & 8.74 & 0.12 & 0.59 & 1.18 \\
& 7 & 65.98 & 8.98 & 0.14 & 0.82 & 1.00 \\
& 15 & 94.07 & 11.48 & 0.17 & 1.06 & 1.49 \\
\hline
\end{tabular}

seen that the creep curves are not smooth, due to a huge amount of microfissures and microcracks in the concrete specimens, leading to closure and collapse under the action of axial stress and resulting in redistribution of internal stress but without affecting the overall deformation law. Simultaneously, it can be seen that, with the increase of 
TABLE 3: The specific creep test plan under different confining pressure.

\begin{tabular}{|c|c|c|c|c|c|c|c|c|}
\hline \multirow{2}{*}{$\begin{array}{l}\text { Confining pressure, } \sigma_{3} \\
(\mathrm{MPa})\end{array}$} & \multirow[b]{2}{*}{$\begin{array}{c}\text { Peak axial deviatoric stress of } \\
\text { TCT, } \sigma \text {-pads }\end{array}$} & \multicolumn{7}{|c|}{ The axial deviatoric stress for each step } \\
\hline & & $\begin{array}{c}\text { Step } 1 \\
10 \%\end{array}$ & $\begin{array}{c}\text { Step } 2 \\
20 \%\end{array}$ & $\begin{array}{c}\text { Step } 3 \\
30 \%\end{array}$ & $\begin{array}{c}\text { Step } 4 \\
40 \%\end{array}$ & $\begin{array}{c}\text { Step } 5 \\
50 \%\end{array}$ & $\begin{array}{c}\text { Step } 6 \\
60 \%\end{array}$ & $\begin{array}{c}\text { Step } 7 \\
70 \%\end{array}$ \\
\hline 0 & 30.56 & 3.06 & 6.11 & 9.17 & 12.22 & 15.28 & $* 18.33$ & \\
\hline 7 & 65.98 & 13.20 & 19.79 & 26.39 & 32.99 & *39.59 & & \\
\hline 15 & 94.07 & 9.41 & 18.81 & 28.22 & $* 37.63$ & & & \\
\hline 22 & 115.54 & 11.55 & 23.10 & $* 34.65$ & & & & \\
\hline
\end{tabular}

According to the final test results, only the tested steps are listed, and the untested steps are not listed. ${ }^{*}$ indicates the creep failure stress under different confining pressures.

confining pressure, the percentage of the peak axial deviatoric stress of TCT $\sigma$-pads (i.e., the creep failure stress) that the composite specimen in the creep tests can bear decreases step-by-step. In the uniaxial state $\left(\sigma_{3}=0 \mathrm{MPa}\right)$, the creep failure stress that the composite specimen can bear is $60 \%$ of its UCS, and the loading step is 6 . When the confining pressure reached $7 \mathrm{MPa}$, the creep failure stress that the composite specimen can bear is $50 \%$ of the peak axial deviatoric stress corresponding to the same confining pressure, and the corresponding loading step is 5 . When the confining pressure increased to $15 \mathrm{MPa}$, the creep failure stress that the composite specimen can bear is $30 \%$ of the corresponding peak axial deviatoric stress, and the corresponding loading step is 3 . Moreover, when the confining pressure increased to $22 \mathrm{MPa}$, the creep failure stress that the composite specimen can bear was only $20 \%$ of its corresponding peak axial deviatoric stress, and the corresponding loading step is 2 .

This is quite different from the creep change rule of conventional pure rock samples under different confining pressures. The phenomenon is caused by the confining pressure and loading history together. On the one hand, due to the gradual transition from brittleness to ductility of concrete samples with the increase of confining pressure $[31,32]$, the deformation capacity increases, elastic modulus and secant modulus decrease, and Poisson's ratio as well as the peak axial strain increases, which leads to the decrease of loading steps of composite samples with the increase of confining pressure. Besides, the loading history is a very important factor in creep response [33, 34]. The larger the axial deviatoric stress, the greater the effect on the deformation of the composite specimen. In other words, the large axial deviatoric stress accelerates the closure of the microcracks and micropore in the composite specimen, thereby accelerating the deformation and failure of the composite specimen. The physical parameters of rock-concrete composite specimens and creep test results under different confining pressures are shown in Table 4.

3.2. Creep Rate Analysis. At the initial stage of stress loading of all steps, the rock-concrete composite specimen undergoes instantaneous elastic strain and then enters the decay creep stage. During the decay creep, the strain value of the composite specimen continuously increases; the strain rate decreases and gradually tends to be stable and then enters the stable creep stage. The initial creep rate of rock-concrete composite specimens with different confining pressures under step loading is shown in Table 5 , and the change trend of step loading rate is shown in Figure 5. When the confining pressure reaches $0 \mathrm{MPa}$, the instantaneous creep rate and the instantaneous elastic strain of the composite specimen are $15.11 \times 10^{-2} / \mathrm{h}$ and $0.04 \%$, respectively. After entering the stable creep stage, the strain value of the composite specimen is stable at $0.0235 \%$ to $0.0311 \%$. When the confining pressure reaches $22 \mathrm{MPa}$, the instantaneous creep rate of the composite specimen is $46.32 \times 10^{-2} / \mathrm{h}$, and the instantaneous elastic strain is $0.23 \%$. After entering the stable creep stage, the strain value of the composite specimen is stable at $0.2510 \%$ to $0.2558 \%$.

According to Table 5 and Figure 5, it can be seen that, with the increase of confining pressure, the initial creep rate of the rock-concrete composite specimen shows a $\mathrm{U}$-shaped trend in the whole creep process and can be roughly divided into three sections: first, there are a large number of micropores and microcracks in the composite specimen, especially in the concrete specimen part, so the composite specimen will produce a huge deformation after being subjected to the Step 1 axial stress, resulting in the instantaneous increases on the instantaneous deformation and initial strain rate of the rock-concrete composite specimen and reaching larger values. The deformation grows rapidly in this stage, and, in the whole creep process, the stage also has the fastest deceleration. Secondly, as time goes by, it gradually enters a stable creep stage. Except for the failure creep stage in the last step, it can be seen that the initial creep rate actually tends to decrease slightly between the other two steps. Finally, when the composite specimen reaches the peak strength and fails, the creep rate increases rapidly in this stage, and the accelerating creep rate also increases gradually with the increase of confining pressure.

By differentiating the time-strain curves in Figures $4(a)-4(d)$, the step loading creep rate under different confining pressures can be obtained. The creep rate under a single loading step is shown in Figure 6. Therefore, the complete fitting curves of step loading rate and initial creep rate under different confining pressures are shown in Figures $7(\mathrm{a})-7(\mathrm{~d})$.

Through analysis, it is found that the decreasing trend of step loading initial creep rate of rock-concrete composite specimens under different confining pressures can be fitted by using power functions. When the confining pressures reach $0 \mathrm{MPa}, 7 \mathrm{MPa}, 15 \mathrm{MPa}$, and $22 \mathrm{MPa}$, 


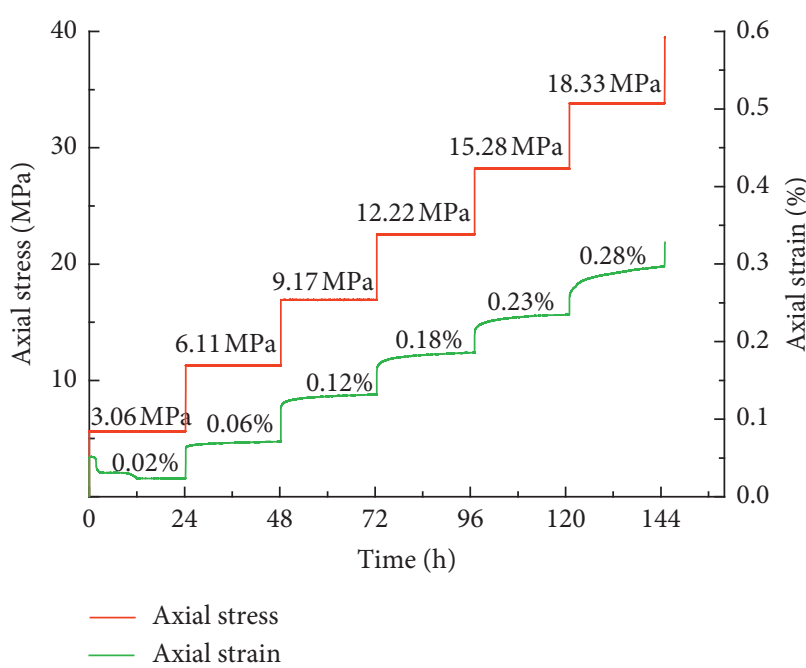

(a)

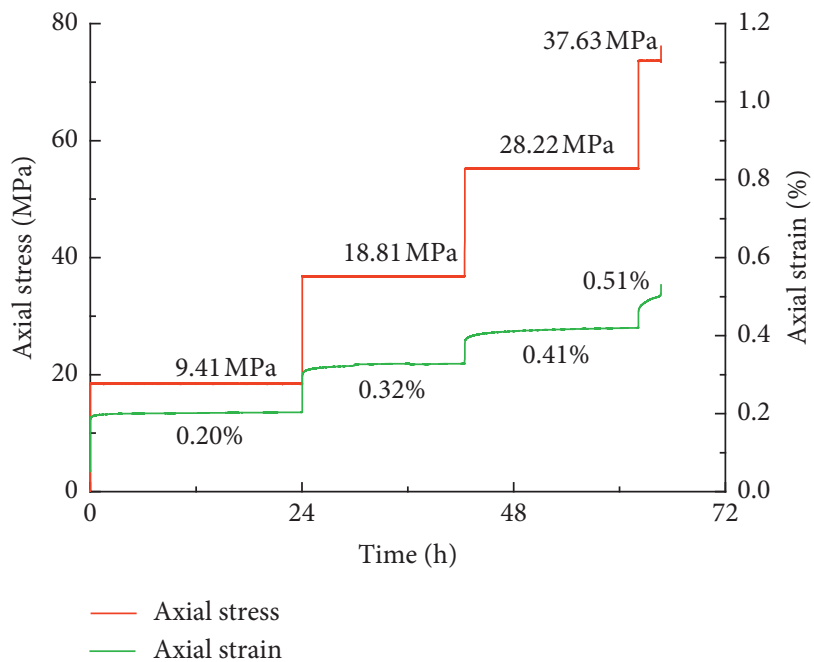

(c)

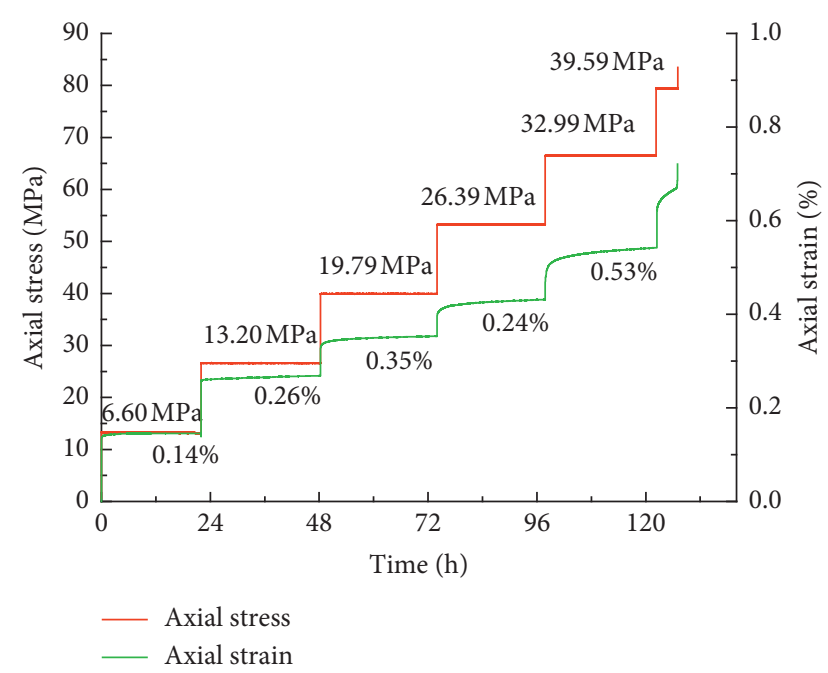

(b)

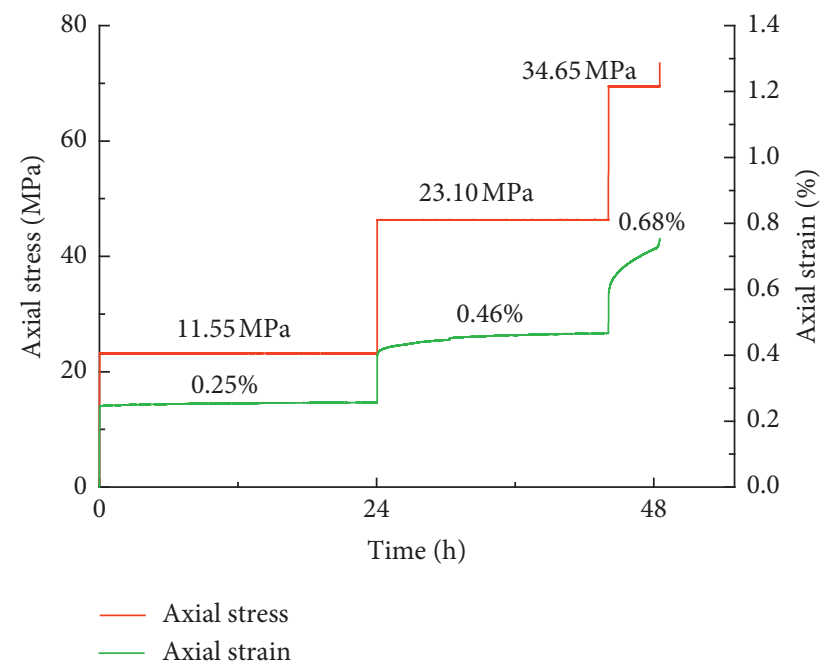

(d)

Figure 4: Step loading time-stress-strain curves of rock-concrete composite specimens under different confining pressures. (a) Confining pressure $0 \mathrm{MPa}$. (b) Confining pressure $7 \mathrm{MPa}$. (c) Confining pressure $15 \mathrm{MPa}$. (d) Confining pressure $22 \mathrm{MPa}$.

TABLE 4: The physical parameters of rock-concrete composite specimens and creep test results under different confining pressures.

\begin{tabular}{lcccccccc}
\hline & $\begin{array}{c}\text { Confining } \\
\text { pressure, } \sigma_{3} \\
(\mathrm{MPa})\end{array}$ & $\begin{array}{c}\text { Diameter, } d \\
(\mathrm{~mm})\end{array}$ & $\begin{array}{c}\text { Height, } h \\
(\mathrm{~mm})\end{array}$ & $\begin{array}{c}\text { Density, } \rho e \\
\left(\mathrm{~kg} / \mathrm{m}^{3}\right)\end{array}$ & $\begin{array}{c}\text { Failure stress, } \\
\sigma_{-f s}(\mathrm{MPa})\end{array}$ & $\begin{array}{c}\text { Instantaneous } \\
\text { strain, } \varepsilon_{i}(\%)\end{array}$ & $\begin{array}{c}\text { Total strain, } \\
\varepsilon_{t}(\%)\end{array}$ & $\varepsilon_{i} / \varepsilon_{t}(\%)$ \\
Rock-concrete & 0 & 49.95 & 99.96 & 2358 & 18.33 & 0.02 & 0.28 \\
composite & 7 & 49.99 & 100.05 & 2389 & 39.59 & 0.14 & 0.53 \\
(triaxial creep) & 15 & 49.97 & 100.02 & 2331 & 37.63 & 0.20 & 0.51 \\
& 22 & 49.98 & 99.98 & 2338 & 34.65 & 0.25 & 39 \\
& & & & & & 0.68 \\
\hline
\end{tabular}

respectively, the initial creep rates meet equations (1)-(4), respectively. The initial creep change trend of rock-concrete composite specimens under different confining pressures obtained through induction and analysis can be used to predict and compare the creep of rock-concrete composite specimens under the same confining pressure.

$$
\begin{aligned}
y & =17.478 x^{-0.951,}, \\
R^{2} & =0.912, \\
y & =22.126 x^{-1.061,} \\
R^{2} & =0.923,
\end{aligned}
$$


TABLE 5: Step loading initial creep rate of rock-concrete composite specimens under different confining pressures.

\begin{tabular}{lccccccc}
\hline \multirow{2}{*}{ Confining pressure $(\mathrm{MPa})$} & \multicolumn{3}{c}{ Axial initial creep rate $\left(10^{-2} / \mathrm{h}\right)$} & & Step 5 & Step 6 & Step 7 \\
\hline 0 & Instantaneous creep rate & Step 2 & Step 3 & Step 4 & 7.93 & 2.03 & $27.75\left(^{*}\right)$ \\
7 & 15.11 & 8.93 & 7.66 & 5.88 & 4.42 & 4.21 & $30.52\left(^{*}\right)$ \\
15 & 24.47 & 15.85 & 9.27 & 7.68 & 5.86 & \\
22 & 38.99 & 14.2 & 8.22 & 6.47 & $38.82\left({ }^{*}\right)$ & \\
\hline
\end{tabular}

$\left({ }^{*}\right)$ is the maximum creep rate of the rock-concrete composite specimen when failure happens.

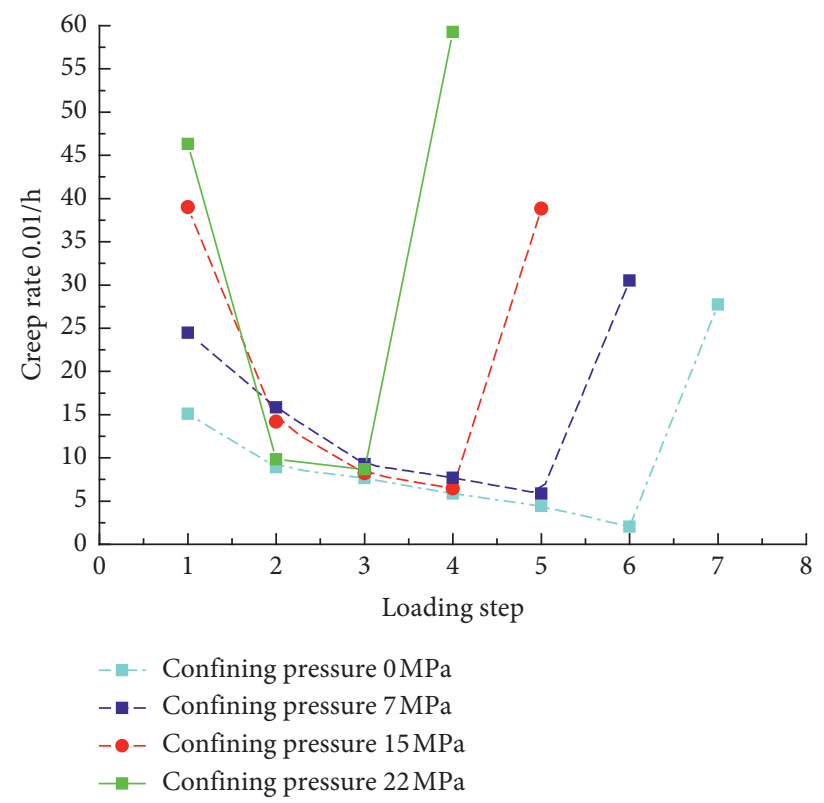

FIGURE 5: Change trend of initial creep rate of rock-concrete composite specimens with different confining pressures under step loading.

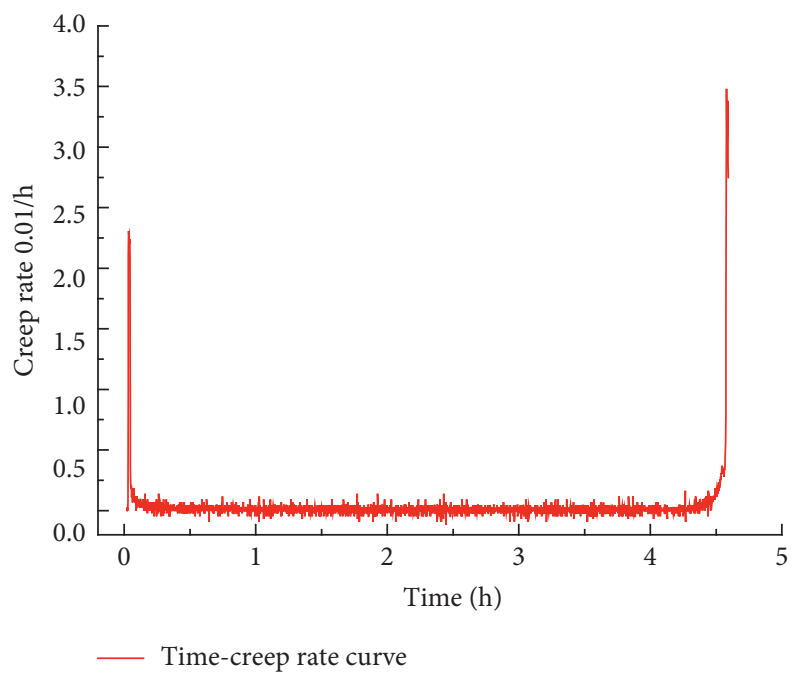

FIGURE 6: Creep time-creep rate curve under a single loading step (taking accelerating creep section at the confining pressure of $7 \mathrm{MPa}$ as an example). 


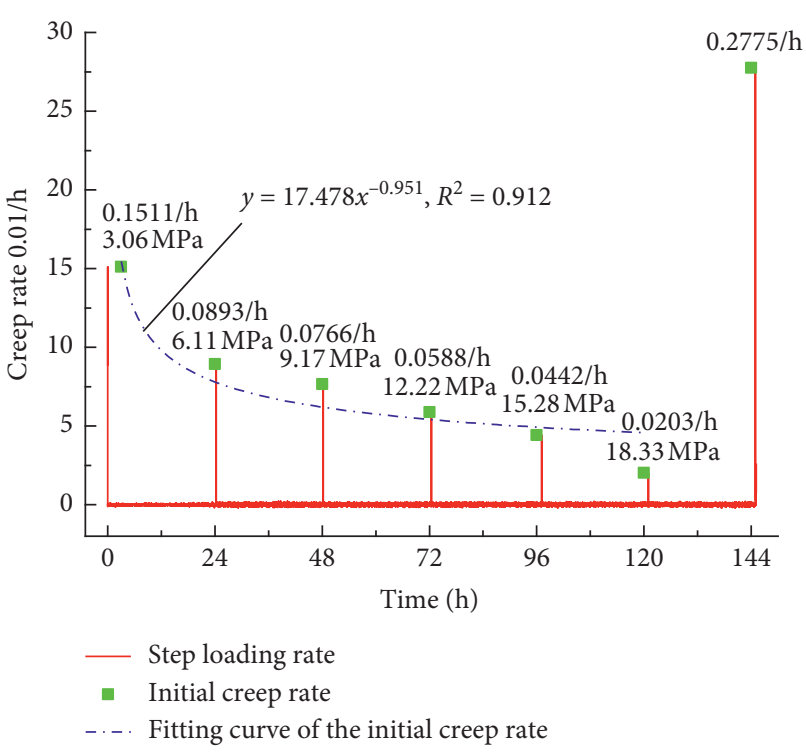

(a)

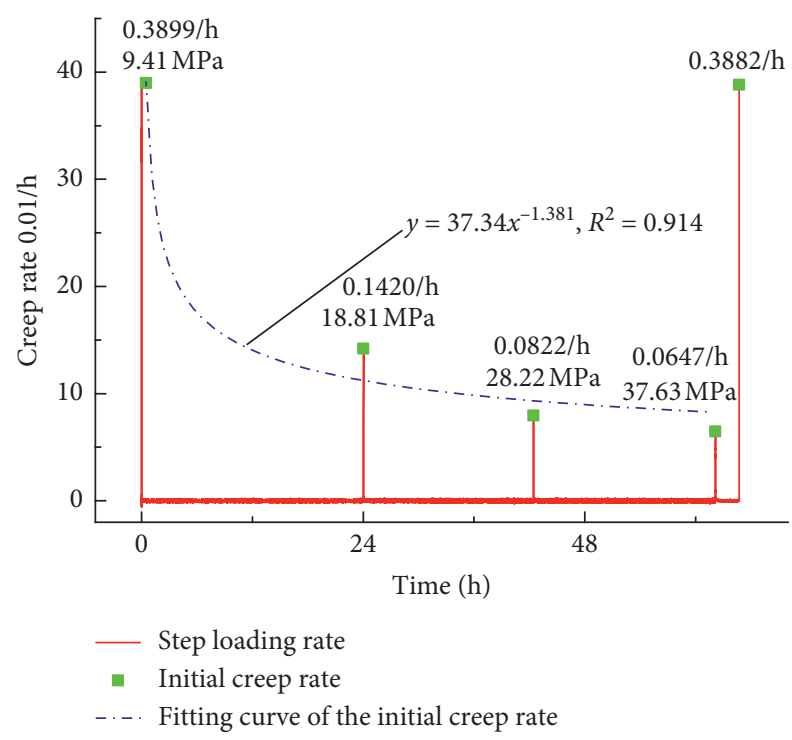

(c)

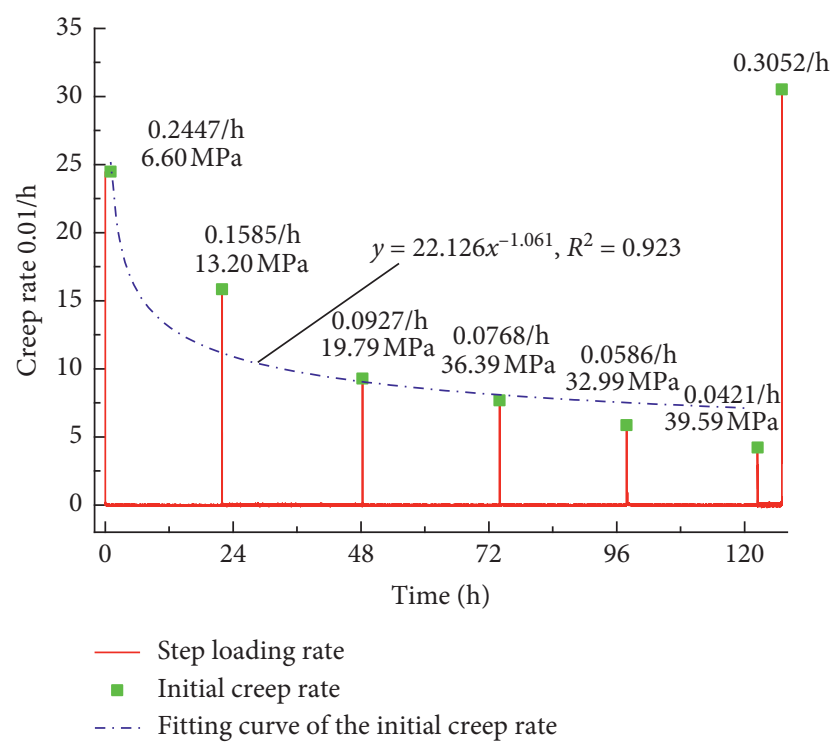

(b)

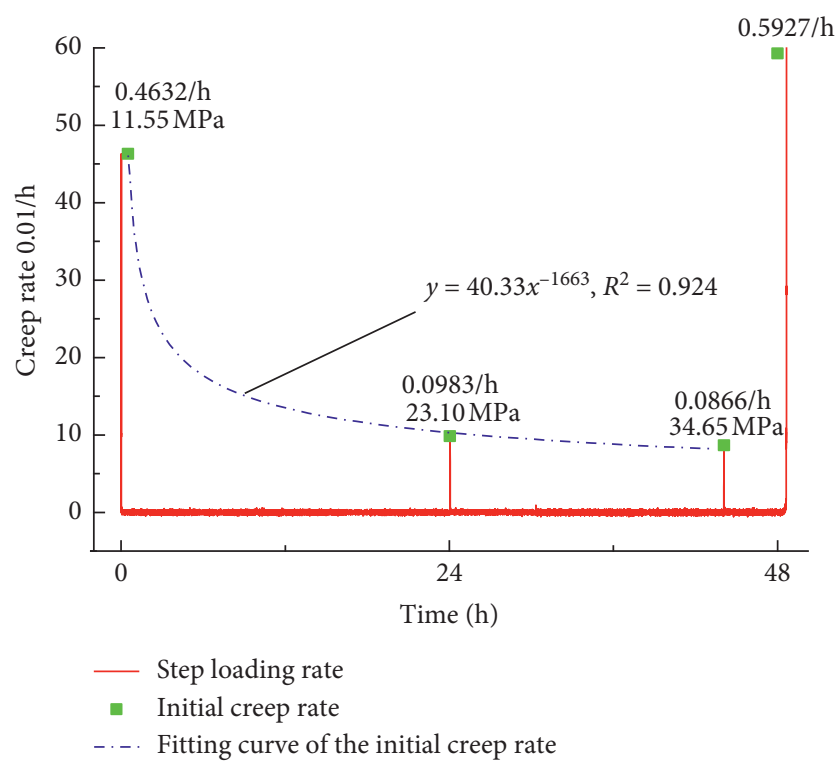

(d)

FigURE 7: Fitting curves of step loading rate and initial creep rate of composite specimens under different confining pressures. (a) Confining pressure $0 \mathrm{MPa}$. (b) Confining pressure $7 \mathrm{MPa}$. (c) Confining pressure $15 \mathrm{MPa}$. (d) Confining pressure $22 \mathrm{MPa}$.

$$
\begin{aligned}
y & =37.34 x^{-1.381,}, \\
R^{2} & =0.914, \\
y & =40.33 x^{-1663}, \\
R^{2} & =0.924 .
\end{aligned}
$$

3.3. Failure Modes. With the increased axial stress, destruction occurs in the composite specimen finally; Figure 8 shows the creep failure mode of the composite specimen under different confining pressures. As can be seen from Figure 8 , the main failure modes of rock-concrete composite specimens are axial splitting failure and bevel shear failure, at the same time, accompanied by local crushing damage. While local crushing damage mostly occurs in the concrete specimen part, the rock parts present less significant damage. In addition, the influence of the confining pressure on the creep failure mode of the composite specimen is not obvious, but, regardless of the composite specimen destruction under whatever confining pressures, the contact surface of the composite sample is always intact, without breakage occurring from the contact surface. Therefore, for composite specimens during creep until final failure, it can be considered that the contact surface does not have too much influence on the mechanical properties of the composite specimens. The ultimate failure of the composite 


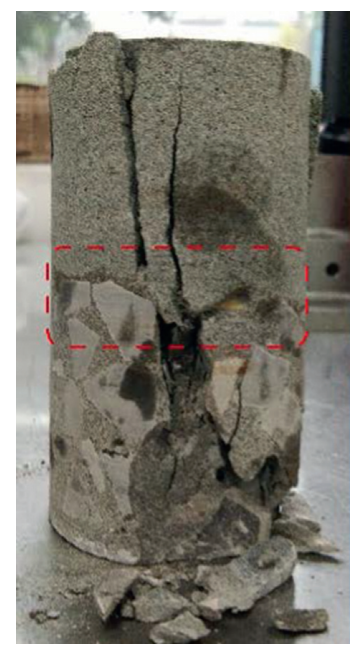

(a)

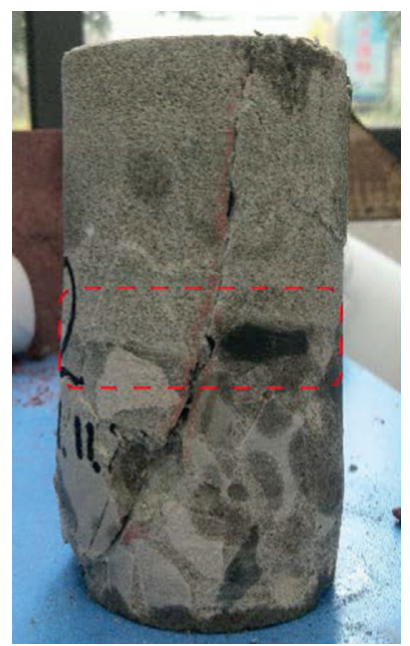

(b)

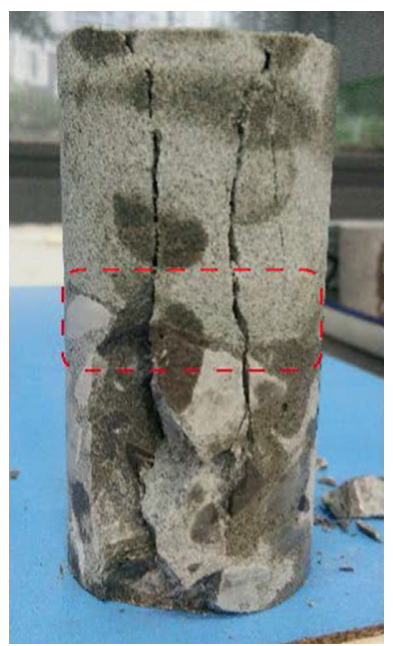

(c)

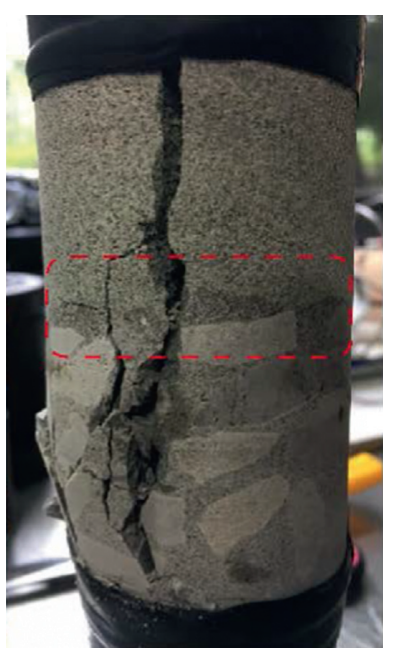

(d)

FIGURE 8: Failure mode of rock-concrete composite specimen under different confining pressures. (a) $0 \mathrm{MPa}$. (b) $7 \mathrm{MPa}$. (c) $15 \mathrm{MPa}$. (d) $22 \mathrm{MPa}$.

specimen can be considered as a result of co-coordinated deformation.

\section{Nonlinear Viscoelastic-Plastic Creep Model for Rock-Concrete Composite Specimens}

4.1. Nishihara Model. Generally speaking, the creep process of rock can be divided into three stages: decelerating creep stage, constant rate creep stage, and accelerating creep stage. The existing Nishihara model can well perform the decelerating creep stage and constant rate creep stage of the rock $[35,36]$; however, since the Nishihara model is composed of ideal linear elements: Hooke body $(\mathrm{H})$, Kelvin body $(\mathrm{N} / \mathrm{H})$, and ideal viscoplastic body (N/St.V), as shown in Figure 9, it cannot accurately describe the third stage of the rock creep process, namely, the accelerating creep stage. Nevertheless, it can be seen from Figures 4(a)-4(d) that the rock-concrete composite specimen has an obvious accelerating creep stage, so the creep process of the rock-concrete composite specimen cannot be directly described by the Nishihara model. In Figure $10, E_{0}$ and $E_{1}$ are the elastic moduli in Hooke and Kelvin bodies, respectively. $\eta_{1}$ and $\eta_{2}$ are the viscosity coefficients of Kelvin body and ideal viscoplastic body, respectively.

The creep equation of Nishihara model is shown in equation (5).

When $\sigma_{0}<\sigma_{s}$, the creep equation of Nishihara model is as follows:

$$
\varepsilon=\frac{\sigma_{0}}{E_{0}}+\frac{\sigma_{0}}{E_{1}}\left[1-\exp \left(-\frac{E_{0}}{\eta_{1}} t\right)\right]
$$

When $\sigma_{0}>\sigma_{s}$, the creep equation of Nishihara model is as follows:

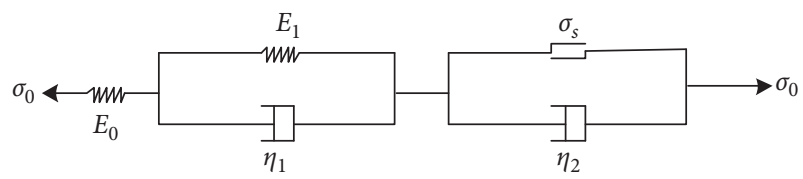

Figure 9: Nishihara model.

$$
\varepsilon=\frac{\sigma_{0}}{E_{0}}+\frac{\sigma_{0}}{E_{1}}\left[1-\exp \left(-\frac{E_{1}}{\eta_{1}} t\right)\right]+\frac{1}{\eta_{2}}\left(\sigma_{0}-\sigma_{s}\right) t,
$$

where $E_{0}, E_{1}, \eta_{1}$, and $\eta_{2}$ are the elastic, plastic, and viscous moduli of the rock, respectively; $\varepsilon$ is the rock strain (\%); $\sigma_{0}$ is the axial stress of the rock (MPa), and $t$ is time (h).

4.2. Nonlinear Viscoelastic-Plastic Creep Model. The rockconcrete composite sample is formed by pouring tight sandstone and concrete with a large number of microcracks and micropores; there is an obvious difference in the internal microstructure between the two materials. According to the scanning electron microscope micrographs of Figures 10(a) and 10(b), it can be clearly seen that there are lots of microcracks and micropores in the concrete sample. However, these microcracks and micropores are caused by drying shrinkage due to evaporation of water inside the concrete sample during solidification. These microcracks and micropores will preferentially compress and close when the concrete sample is subjected to external force. While the microstructure of the rock sample is compact and orderly, it can be clearly seen that the rock crystals are tightly bound together, and there are almost no obvious microcracks or micropores.

Therefore, the creep process of the rock-concrete composite sample can be divided into three stages. In the first stage $T_{1}$, when the composite sample is subjected to axial stress, the low-strength concrete specimen with large 


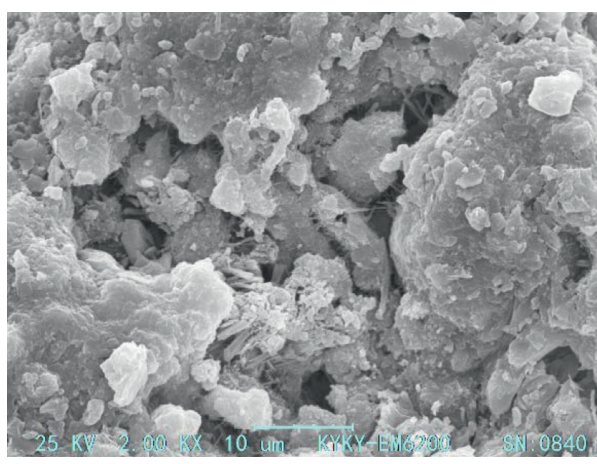

(a)

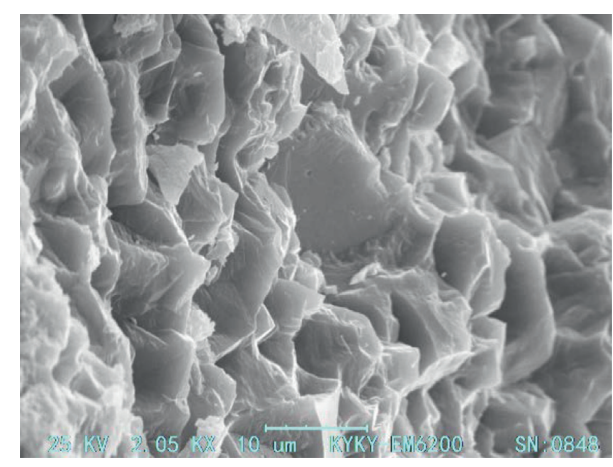

(b)

Figure 10: Microstructure of concrete and rock specimens when magnified 2000 times, respectively. (a) Concrete specimen. (b) Rock specimen.

numbers of microcracks and micropores will be compacted first, while the deformation of the rock sample is very small. Meanwhile, the deformation and stress are linearly elastic. In the second stage $T_{2}$, with the gradual increase of axial stress, most of microcracks and micropores in the concrete are closed. At this time, the rock and the concrete will begin to deform coordinately and jointly produce deformation. In the third stage $T_{3}$, the composite specimen reaches the axial peak stress, causing failure and accelerating creep. By the above analysis, a new creep constitutive model is proposed to describe the creep process of rock-concrete composite specimen. The new constitutive model is obtained by improving the Nishihara constitutive model. The improved Nishihara constitutive model corresponding to the specific creep process is shown in Figure 11.

Based on the analysis of the deformation process of the rock-concrete composite specimen, the improvement of the Nishihara model mainly includes the following: based on the original model, a nonlinear viscoplastic body is connected in series, and the main function of the viscoplastic body is to embody the accelerating creep process of the rock-concrete composite sample. According to the improved Nishihara model in Figure 11, the following can be obtained:

$$
\left\{\begin{array}{l}
\sigma=\sigma_{1}=\sigma_{2}=\sigma_{3}=\sigma_{4} \\
\varepsilon=\varepsilon_{1}+\varepsilon_{2}+\varepsilon_{3}+\varepsilon_{4}
\end{array}\right.
$$

where each stress-strain relation satisfies equation (8).

$$
\left\{\begin{array}{l}
\sigma_{1}=E_{0} \varepsilon_{1}, \\
\sigma_{2}=E_{1} \varepsilon_{2}+\eta_{1} \varepsilon_{2}^{\prime}, \\
\sigma_{3}=\sigma_{S 1}+\eta_{2} \varepsilon_{3}^{\prime}, \\
\sigma_{4}=\frac{\sigma_{S 2}+\eta_{3} \varepsilon_{4}^{\prime}}{\left(a t^{b}\right)}
\end{array}\right.
$$

After sorting out equations (7) and (8), the following can be obtained:

$$
\begin{aligned}
\sigma^{\prime \prime} & +\left(\frac{E_{0}+E_{1}}{\eta_{1}}+\frac{E_{1}}{\eta_{2}}+\frac{E_{1} t^{b}}{\eta_{3}}\right) \sigma^{\prime}+\left(\sigma-\sigma_{s 1}\right) \frac{E_{0} E_{1}}{\eta_{1} \eta_{2}} \\
+ & \frac{E_{1}\left(\sigma-\sigma_{S 2}\right)}{\eta_{3}}\left[a b t^{b-1}+\frac{E_{1}}{\eta_{1}} a t^{b}\right]=E_{1} \varepsilon^{\prime \prime}+\frac{E_{0} E_{1}}{\eta_{1}} \varepsilon^{\prime} .
\end{aligned}
$$

The creep equation of rock-concrete composite specimen obtained by Laplace transformation of equation (9) is as follows:

$$
\begin{aligned}
\mathcal{E}= & \frac{\sigma_{0}}{E_{0}}+\frac{\sigma_{0}}{E_{1}}\left[1-\exp \left(-\frac{E_{1}}{\eta_{1}} t\right)\right]+\frac{1}{\eta_{2}}\left(\sigma_{0}-\sigma_{s 1}\right) t_{1} \\
& +\frac{1}{\eta_{3}}\left(\sigma_{0}-\sigma_{s 2}\right) t_{2}^{n},
\end{aligned}
$$

where $E_{0}, E_{1}, \eta_{1}, \eta_{2}$, and $\eta_{3}$ are, respectively, 2 elastic coefficients and 3 viscosity coefficients of rock-concrete composite specimens; $\varepsilon$ is strain of rock-concrete composite specimen, $\% ; \sigma_{0}$ is the axial stress of the rock-concrete composite specimen, MPa; $t$ is the total creep time, $t_{1}$ is the starting time for linear viscoplastic body to participate in creep, and $t_{2}$ is starting time for accelerating creep, h; $\sigma_{s 1}$ is the creep initial strength of the rock-concrete composite specimen, $\mathrm{MPa} ; \sigma_{s 2}$ is the long-term strength of the rockconcrete composite specimen, $\mathrm{MPa}$.

\subsection{Model Parameter Identification and Model Verification.} Taking the test data under $7 \mathrm{MPa}$ confining pressure to identify and verify the creep parameters of the improved model, it is found that there is a critical stress value during the creep of the rock-concrete composite specimen. When the applied stress is less than the critical stress value, the creep is stable; that is, the rock failure will not occur with the increase of time. When the time stress (axial deviatoric stress) is greater than the critical stress value, the creep is unstable; that is, the rock failure will occur with the increase of time, and this critical value is the long-term strength. Among them, the families of the isochronous stress-strain curve method $[37,38]$ are a widely used method and it has been incorporated into rock test specifications. According to the families of the isochronous stress-strain curves of the 


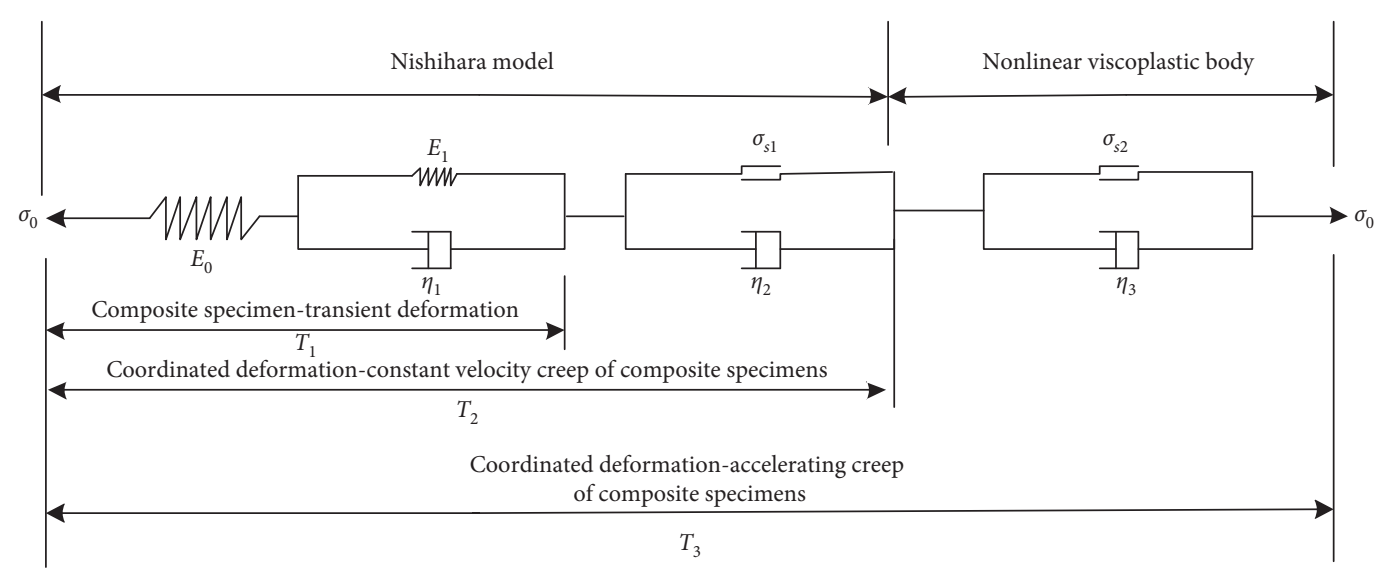

FIGURE 11: Improved Nishihara model.

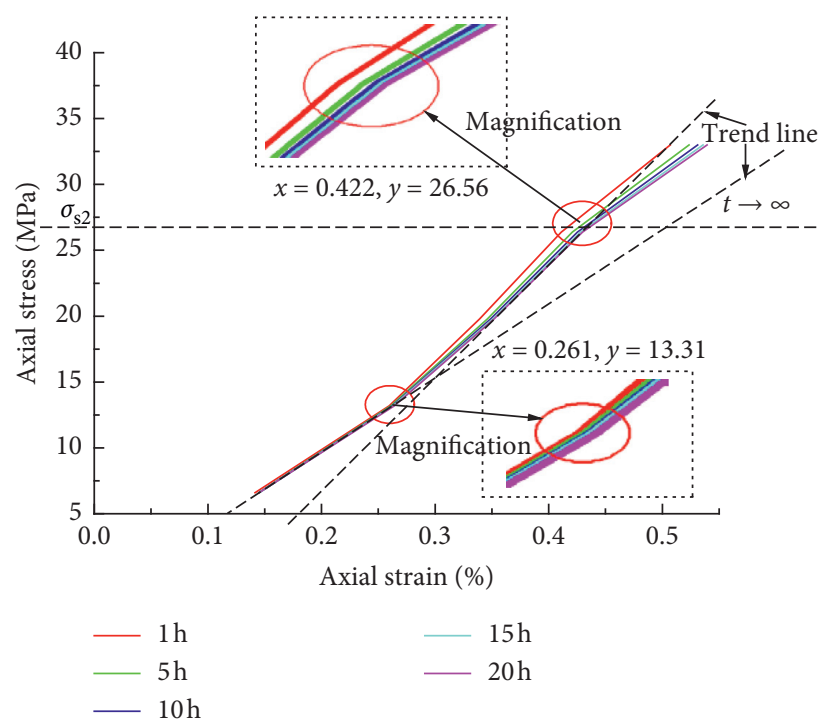

FIGURE 12: Families of isochronous stress-strain curves of rock-concrete composite specimens under the confining pressure of $7 \mathrm{MPa}$.

rock-concrete composite specimen under the confining pressure of $7 \mathrm{MPa}$ shown in Figure 12, it can be seen that the families of the isochronous stress-strain curves have obvious inflection points when the axial stress $\sigma_{0}=13.31 \mathrm{MPa}$ and $\sigma_{0}=26.56 \mathrm{MPa}$. At the first inflection point, $\sigma_{0}=\sigma_{s 1}=13.31 \mathrm{MPa}$, and the families of curves after the second inflection point will gradually become parallel to $X$ axis with the increase of time. According to the corresponding change trend, it can be seen that, with the increase of time, the second half of the corresponding curve tends to be a straight smooth line.

Therefore, when the confining pressure reaches $7 \mathrm{MPa}$, the axial stress $\sigma_{0}=\sigma_{s 2}=26.56 \mathrm{MPa}$, that is, the long-term strength value of the rock. Then 1st Opt software is used, and Levenberg-Marquardt as well as the General Global Optimization method is adopted to fit the curve. There is no need to use the initial value of the parameters for calculation, and the software will automatically give the optimal solution of the undetermined parameters according to the global optimization algorithm. Therefore, when the confining pressure reaches $7 \mathrm{MPa}$, all parameters of the improved Nishihara model are shown in Table 6.

Figure 13 is a comparison figure between the fitting curve and the test curve of the improved Nishihara model of the rock-concrete composite specimen under the confining pressure of $7 \mathrm{MPa}$. The improved Nishihara model can not only restore the creep process of the rock-concrete composite specimen without accelerating creep under low confining pressure but also restore the creep process of the rock-concrete composite specimen with accelerating creep under high confining pressure. The correlation coefficient $R^{2}$ of fitting under $7 \mathrm{MPa}$ is 0.945 , which verifies the precision and accuracy of the improved Nishihara model for creep process simulation of rock-concrete composite specimens.

As shown in Figure 14, the accelerating creep curve of the rock-concrete composite specimen is fitted with the improved Nishihara model and the original Nishihara model, respectively, and then compared. It can be clearly seen that the accelerating creep section cannot be fitted by using the original Nishihara model, while the improved 
TABLE 6: Parameters of the improved Nishihara model for rock-concrete composite specimens under the confining pressure of 7 MPa.

\begin{tabular}{lcccrrr}
\hline Axial stress $(\mathrm{MPa})$ & $E_{0}(\mathrm{MPa})$ & $E_{1}(\mathrm{MPa})$ & $\eta_{1}(\mathrm{MPa} \cdot \mathrm{h})$ & $\eta_{2}(\mathrm{MPa} \cdot \mathrm{h})$ & $\eta_{3}(\mathrm{MPa} \cdot \mathrm{h})$ & $n$ \\
\hline 6.60 & 95.69 & 1811.38 & 3266.33 & & \\
13.20 & 102.54 & 2955.27 & 7695.78 & & 0.954 \\
19.79 & 120.30 & 2744.09 & 4171.33 & 39367.41 & 0.972 \\
26.39 & 131.99 & 2883.72 & 4981.11 & 51656.32 & 0.949 \\
32.99 & 136.86 & 1786.77 & 2391.15 & 56471.60 & 44143.79 & 0.985 \\
39.59 & 156.95 & 3578.24 & 5794.31 & 49782.37 & 48671.23 & 0.986 \\
\hline
\end{tabular}

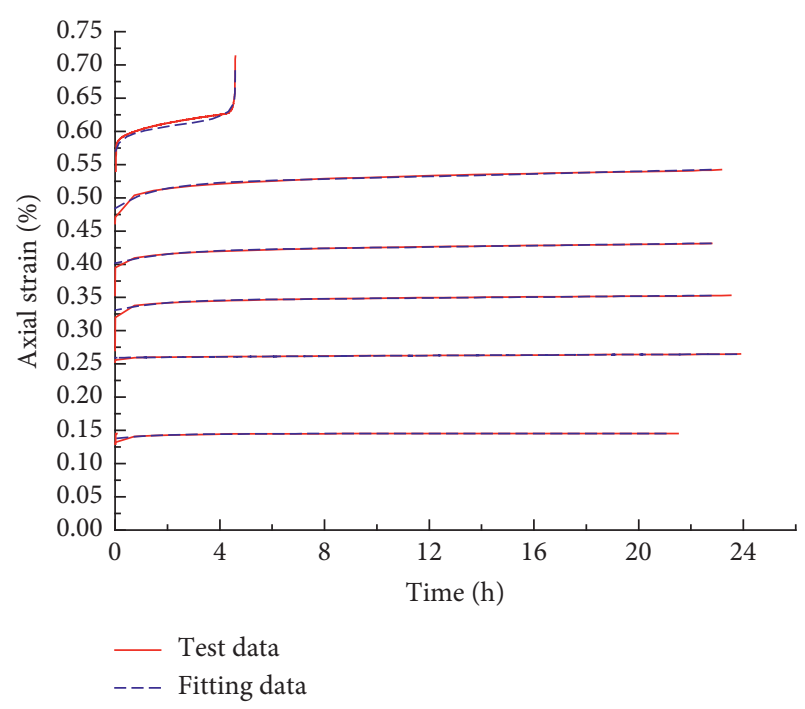

FIGURE 13: Comparison between the fitting curve and the test curve of the improved Nishihara model under the confining pressure of $7 \mathrm{MPa}$.

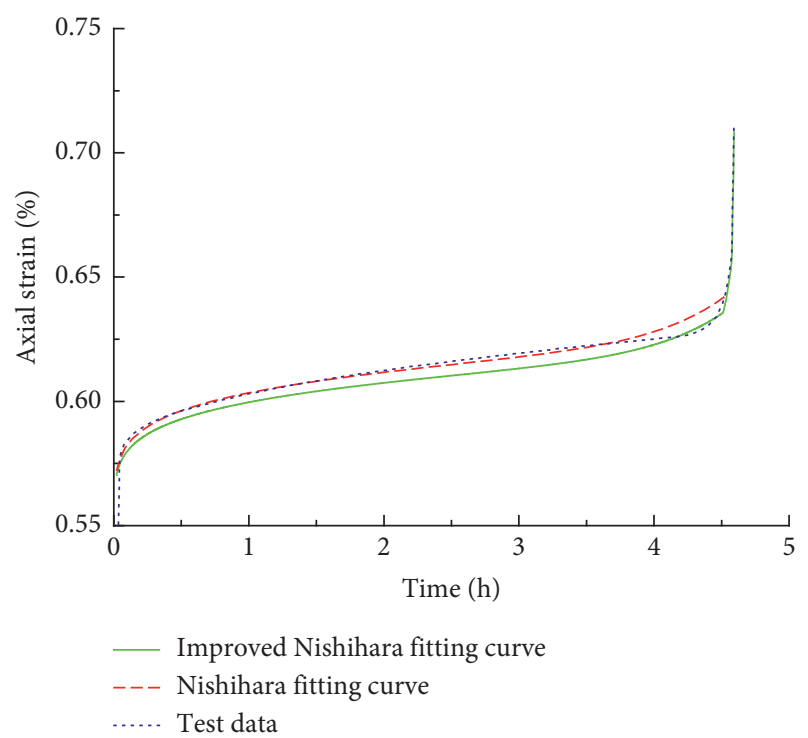

FIGURE 14: Comparison of accelerating creep curves and test curves of two creep models.

Nishihara model can. In addition, the fitting similarity coefficient $R^{2}$ of the original Nishihara model is 0.814 , while the similarity coefficient $R^{2}$ of the improved Nishihara model is 0.945 .

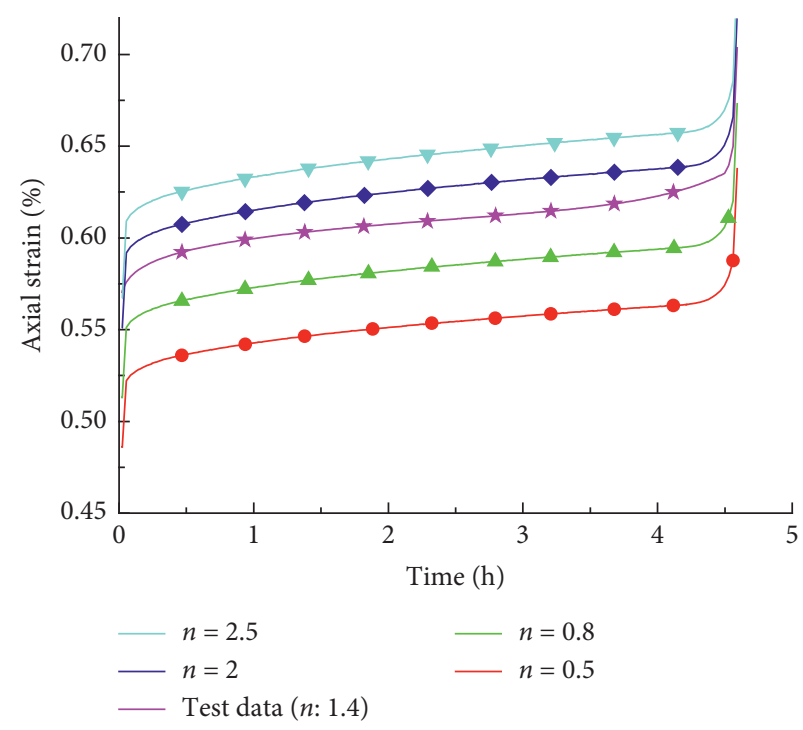

FIGURE 15: Sensitivity analysis of creep equation parameter $n$.

4.4. Discussion on the Sensitivity of Parameter $n$ of the Creep Equation. In order to determine the influence of the sensitivity coefficient $n$ in the creep equation of the improved Nishihara model on the accelerating creep curve fitting of the rock-concrete composite sample, $0.5,0.8,1.4,2$, and 2.5 are taken, respectively, for analysis and comparison. The comparison curves of five different sensitivity coefficients are shown in Figure 15. As shown in Figure 15, it can be seen that when $n$ is equal to 0.5 or 0.8 , the theoretical value obtained will be smaller than the test value, while when $n$ is equal to 2 or 2.5 , the fitting value obtained will be larger than the test value.

\section{Conclusions}

Based on the step loading triaxial creep tests of rock-concrete composite specimens under different confining pressures, with focus on the analysis of the creep rate and its change trend of the rock-concrete composite specimens, the creep process of the rock-concrete composite specimens is described by using the improved Nishihara model, and the following conclusions are obtained:

(1) The rock-concrete composite specimen has remarkable creep characteristics; during the creep process, the creep failure stress that the composite specimen can bear is closely related to the confining pressure. When the confining pressure reaches $0 \mathrm{MPa}, 7 \mathrm{MPa}, 15 \mathrm{MPa}$, and $22 \mathrm{MPa}$, the creep failure 
stress that the composite specimen can bear is $60 \%$, $50 \%, 30 \%$, and $20 \%$, respectively, of the UCS and TCS under the same confining pressure.

(2) Under the same confining pressure, the initial creep rate of the rock-concrete composite specimen shows a U-shaped change trend; meanwhile, the instantaneous creep rate and the failure creep rate of the rock-concrete composite specimen both increase with the increase of confining pressure. Apart from the failure creep rate, the other step loading initial creep rates under the same confining pressure decrease step-by-step.

(3) The creep process of rock-concrete composite specimens can be described very well by using the improved Nishihara model, especially in the accelerating creep stage of rock-concrete composite specimens. By comparing and analyzing the fitting curve obtained by the improved Nishihara model with the fitting curve and test curve obtained by the original Nishihara model, it can be seen that the similarity coefficient $R^{2}$ of the improved Nishihara model is 0.945 , which is greatly improved compared with the similarity coefficient of the Nishihara model, $R^{2}=0.814$, and the improved Nishihara model is more fitted with the test curve, thus verifying the precision and accuracy of the improved creep model.

\section{Data Availability}

The data used to support the findings of this study are included within the article.

\section{Conflicts of Interest}

The authors declare no conflicts of interest.

\section{Acknowledgments}

This work was supported by the National Natural Science Foundation of China (nos. 41672300, 41807279, and 41972297), the Supporting Program of Hundred Promising Innovative Talents in Hebei Provincial Education Office (no. SLRC2019027), Chongqing Municipal Natural Science Foundation (no. cstc2020jcyj-msxm1078), and the key laboratory of well stability and fluid and rock mechanics in Oil and Gas Reservoir of Shaanxi Province, Xi'an Shiyou University (no. FRM20190201002).

\section{References}

[1] M. D. Granrut, A. Simon, and D. Dias, "Artificial neural networks for the interpretation of piezometric levels at the rock-concrete interface of arch dams," Engineering Structures, vol. 178, pp. 616-634, 2019.

[2] Y. Shen, Y. Wang, Y. Yang, Q. Sun, T. Luo, and H. Zhang, "Influence of surface roughness and hydrophilicity on bonding strength of concrete-rock interface," Construction and Building Materials, vol. 213, pp. 156-166, 2019.

[3] Y. A. Fishman, "Stability of concrete retaining structures and their interface with rock foundations," International Journal of Rock Mechanics and Mining Sciences, vol. 46, no. 6, pp. 957-966, 2009.

[4] Y. A. Fishman, "Features of shear failure of brittle materials and concrete structures on rock foundations," International Journal of Rock Mechanics and Mining Sciences, vol. 45, no. 6, pp. 976-992, 2008.

[5] V. Sujatha and J. M. C. Kishen, "Energy release rate due to friction at bimaterial interface in dams," Journal of Engineering Mechanics, vol. 129, no. 7, pp. 793-800, 2003.

[6] M. Flansbjer and J. Magnusson, "System design of dome plug mechanical properties of rock-concrete interface," Report No. P-13-38, Swedish Nuclear Fuel and Waste Management Co, Vol. 53, Stockholm, Sweden, 2014.

[7] Y. Zhao, Y. Wang, W. Wang, W. Wan, and J. Tang, "Modeling of non-linear rheological behavior of hard rock using triaxial rheological experiment," International Journal of Rock Mechanics and Mining Sciences, vol. 93, pp. 66-75, 2017.

[8] S. Zhang, W. Liu, and H. Lv, "Creep energy damage model of rock graded loading," Results in Physics, vol. 12, pp. 1119$1125,2019$.

[9] M. Hadiseh and A. Rassoul, "Mechanical behavior of salt rock under uniaxial compression and creep tests," International Journal of Rock Mechanics and Mining Sciences, vol. 110, pp. 19-27, 2018.

[10] J. R. H. Nicholas, R. F. Weinberg, C. J. L. Wilson, V. Luzn, and S. Misra, "Quartz deformation across interlayered monomineralic and polymineralic rocks: a comparative analysis," Journal of Structural Geology, vol. 119, pp. 118134, 2019.

[11] S. He, Z. Zhu, M. Lv, and H. Wang, "Experimental study on the creep behaviour of rock-filled concrete and self-compacting concrete," Construction and Building Materials, vol. 186, pp. 53-61, 2018.

[12] C. Laurent, L. P. Yann, C. Éric et al., "A 12 year EDF study of concrete creep under uniaxial and biaxial loading," Cement and Concrete Research, vol. 103, pp. 140-159, 2018.

[13] C. Laurent and S. Julien, "Creep and relaxation Poisson's ratio: back to the foundations of linear viscoelasticity. Application to concrete," International Journal of Solids and Structures, vol. 1110-111, pp. 2-14, 2017.

[14] F. Mounia, S. Jacqueline, G. Frédéric, and L. Ahmed, "7-multi-scale methods for the analysis of creep-damage coupling in concrete," in Advances in Multi-Physics and Multi-Scale Couplings in Geo-Environmental Mechanics, pp. 205-241, Elsevier, Amsterdam, Netherlands, 2018.

[15] B. Alan and S. Jiang, "Numerical analysis and capacity evaluation of composite sprayed concrete lined tunnels," Underground Space, vol. 3, no. 2, pp. 87-108, 2018.

[16] E. Stavropoulou, M. Briffaut, F. Camps, and C. Guillaume, "Experimental characterisation of the mechanical properties of the clay-rock/concrete interfaces and their evolution in time," in Challenges in Mechanics of Time Dependent Materials, vol. 2, pp. 1-3, Springer, Cham, Switzerland, 2018.

[17] M. Hussein, B. Marion, L. Madly, and V. Didier, "Experimental study of the shear strength of bonded concrete-rock interfaces: surface morphology and scale effect," Rock Mechanics and Rock Engineering, vol. 50, no. 10, pp. 2601-2625, 2017.

[18] L. B. F. Maria, M. A. Nuno, and C. Mariline, "Small displacement coupled analysis of concrete gravity dam foundations: static and dynamic conditions," Rock Mechanics and Rock Engineering, vol. 50, no. 2, pp. 439-464, 2017. 
[19] W. Zhao, W. Chen, and K. Zhao, "Laboratory test on foamed concrete-rock joints in direct shear," Construction and Building Materials, vol. 173, pp. 69-80, 2018.

[20] D. Wei, Z. M. Wu, X. M. Zhou, N. Wang, and G. Kastiukas, "An experimental study on crack propagation at rock-concrete interface using digital image correlation technique," Engineering Fracture Mechanics, vol. 171, pp. 50-63, 2017.

[21] E. Stavropoulou, M. Briffaut, F. Dufour, and G. Camps, "Time-dependent behaviour of the Callovo-Oxfordian claystone-concrete interface," Journal of Rock Mechanics and Geotechnical Engineering, vol. 12, no. 1, pp. 89-101, 2020.

[22] O. Buzzi, M. Boulon, M. Hervé, and K. Su, "Leaching of rockconcrete interfaces," Rock Mechanics and Rock Engineering, vol. 41, no. 3, pp. 445-466, 2007.

[23] B. Zhao, Y. Liu, T. Huang, and X. Wang, "Experimental study on strength and deformation characteristics of rock-concrete composite specimens under compressive condition," Geotechnical and Geological Engineering, vol. 37, no. 4, pp. 2693-2706, 2019.

[24] ASTM C150/C150M-19a, Standard Specification for Portland Cement, ASTM International, West Conshohocken, PA, USA, 2019.

[25] ASTM C136/C136M-14, Standard Test Method for Sieve Analysis of Fine and Coarse Aggregates, ASTM International, West Conshohocken, PA, USA, 2014.

[26] ASTM C128-15, Standard Test Method for Relative Density (Specific Gravity) and Absorption of Fine Aggregate, ASTM International, West Conshohocken, PA, USA, 2015.

[27] ASTM C172/C172M-17, Standard Practice for Sampling Freshly Mixed Concrete, ASTM International, West Conshohocken, PA, USA, 2017.

[28] ASTM C1140/C1140M-11, Standard Practice for Preparing and Testing Specimens from Shotcrete Test Panels, ASTM International, West Conshohocken, PA, USA, 2011.

[29] C. E. Fairhurst and J. A. Hudson, "Draft ISRM suggested method for the complete stress train curve for the intact rock in uniaxial compression," International Journal of Rock Mechanics and Mining Sciences, vol. 36, no. 3, pp. 279-289, 1993.

[30] ASTM D7070-16, Standard Test Methods for Creep of Rock Core under Constant Stress and Temperature, ASTM International, West Conshohocken, PA, USA, 2016.

[31] R. J. M. Wolfs, F. P. Bos, and T. A. M. Salet, "Triaxial compression testing on early age concrete for numerical analysis of 3D concrete printing," Cement and Concrete Composites, vol. 104, p. 103344, 2019.

[32] E. Papa and A. Taliercio, "Anisotropic damage model for the triaxial creep behaviour of plain concrete," in Damage Mechanics in Engineering Materials, pp. 337-350, Elsevier, Amsterdam, Netherlands, 1998.

[33] I. Boumakis, M. Marcon, K. Ninčević, L.-M. Czernuschka, and R. Wan-Wendner, "Concrete creep and shrinkage effect in adhesive anchors subjected to sustained loads," Engineering Structures, vol. 175, pp. 790-805, 2018.

[34] A. B. Giorla and C. F. Dunant, "Microstructural effects in the simulation of creep of concrete," Cement and Concrete Research, vol. 105, pp. 44-53, 2018.

[35] H. W. Zhou, C. P. Wang, B. B. Han, and Z. Q. Duan, “A creep constitutive model for salt rock based on fractional derivatives," International Journal of Rock Mechanics and Mining Sciences, vol. 48, no. 1, pp. 116-121, 2011.

[36] X. Li, C. Yang, T. Ren et al., "Creep behaviour and constitutive model of coal filled with gas," International Journal of Mining Science and Technology, vol. 27, no. 5, pp. 847-851, 2017.

[37] X. Zhao, B. Chen, H. Zhao, B. Jie, and Z. Ning, "Laboratory creep tests for time-dependent properties of a marble in
Jinping II hydropower station," Journal of Rock Mechanics and Geotechnical Engineering, vol. 4, no. 2, pp. 168-176, 2012.

[38] M. Aubertin, L. Li, and R. Simon, "A multiaxial stress criterion for short- and long-term strength of isotropic rock media," International Journal of Rock Mechanics and Mining Sciences, vol. 37, no. 8, pp. 1169-1193, 2000. 